\title{
Análise do desempenho de concretos com diferentes métodos de inserção de silicato de sódio neutro para autocicatrização
}

\author{
F P de Souza ${ }^{1}$, F. Pacheco ${ }^{2 *}$, R. P de Souza ${ }^{3}$; H.Z. Ehrenbring ${ }^{4}$; R.C.E. Modolo ${ }^{5}$, B.F. Tutikian ${ }^{6}$ \\ *Autor de Contacto: fernandapache@unisinos.br \\ 1,5 Escola Politénica, Graduação em Engenharia Civil, UNISINOS, São Leopoldo, Brasil \\ 2,4,6 Unidade de pesquisa e pós-graduação- itt Performance, UNISINOS, São Leopoldo, Brasil \\ 3, 5 Unidade de pesquisa e pós-graduação- PPGEC- Programa de pós graduação em Engenharia Civil, UNISINOS,
}

São Leopoldo, Brasil

\section{RESUMEN}

Uma das soluções que tem ganhado destaque nos concretos autocicatrizantes é a utilização de soluções químicas, como o de silicato de sódio neutro. A solução de tal produto pode ser encapsulada, adicionada na água de mistura e/ou aspergida em concretos. Sua atuação se dá com a reação do silicato e hidróxido de cálcio em pasta de cimento hidratado, formando assim um gel de silicato de cálcio hidratado, este por sua vez depositando-se ao longo das aberturas das fissuras dos elementos em concreto, promovendo assim a cicatrização. Esse trabalho teve como objetivo avaliar essas diferentes formas de uso da solução. Para tal, foram desenvolvidas amostras com o silicato encapsulado em perlita expandida, na água de amassamento e com sua aspersão diretamente nas fissuras. Para caracterizar as matrizes utilizou-se de ensaios como os de resistência a compressão uniaxial, e de absorção. Para a indução de fissuras foi aplicado o ensaio de tração na flexão. Para avaliar a cicatrização das fissuras foi feita análise visual e utilização de software gráfico para mensuração dos percentuais de fissuras cicatrizadas. Percebeu-se que determinadas soluções contendo o silicato de sódio, principalmente a PER.VAC (com perlitas encapsuladas à vácuo) e a SIL.ASP (com aspersão do silicato de sódio nas fissuras) obtiveram sucesso quanto a autocicatrização, apresentando potencial pela caracterização e verificação da autorregeneração dos protótipos de vigas.

Palabras clave: Autorregenerantes, autocicatrizante e hidrato de silicato de cálcio.

\begin{abstract}
One of the solutions that stand out in the design of self-healing concretes is the use of chemical solutions, such as neutral sodium silicate. This solution can be encapsulated, added to the mixing
\end{abstract}


water, or sprayed on concrete. Its performance occurs with the reaction of calcium silicate and hydroxide in hydrated cement paste, thus forming a hydrated calcium silicate gel, which in turn deposits itself along the crack openings of the concrete elements, thus promoting the healing. This work aimed to evaluate these different ways of using the solution. For this, samples were developed with the silicate encapsulated in expanded perlite, in the mixing water, and with its sprinkling directly into the cracks. To characterize the matrices, tests such as resistance to uniaxial compression and absorption were used. For the induction of cracks, the flexural tensile test was applied. To assess the healing of fissures, visual analysis and graphic software were used to measure the percentage of healed fissures. It was noticed that certain solutions containing sodium silicate, mainly PER.VAC (with vacuum encapsulated perlites) and SIL.ASP (with spraying of sodium silicate in cracks) were successful in self-healing, presenting potential for the characterization and verification of the self-regeneration of beam prototypes.

Keywords: Self-healing, self-healing and calcium silicate hydrate.

\section{INTRODUCCIÓN}

Estruturas de concreto armado são sujeitas a ocorrência de fenômenos patológicos, tais como o surgimento de fissuras, o que pode resultar em perda de desempenho e funcionalidade a longo prazo (Bonic et al, 2015; Zai; Murphy, 2015). Havlásek et al. (2017) citam que diversos são os motivos para seu aparecimento, e podem ocorrer em diferentes fases. Normas técnicas internacionais estipulam limites para a abertura das fissuras, justamente por entender-se seu potencial de dano (ABNT NBR 6118; ACI Comittee 224; IS 456; Fib Bulletin 34)

Considerando tal dano, estudam-se na atualidade mecanismos que possam promover a autocicatrização do concreto. Há a possibilidade de cicatrização autógena, conhecida como aquela que ocorre com os materiais convencionalmente empregados, tais como cimento ou adições pozolânicas, devido à formação secundária de silicato de cálcio hidratado (Hoppe Filho et al, 2017)

Porém, tais mecanismos autogênicos têm limitações no que se refere a idade de surgimento da fissura, a capacidade máxima de cicatrização, e ainda, a disposição das partículas. Assim sendo, tem-se o destaque para os mecanismos autônomos. Dentre os autônomos, tem destaque na bibliografia o uso de soluções químicas e biológicas. Devido à complexidade dos fenômenos que envolvem soluções bacterianas e sua difícil preparação em elementos de tamanho real (Adak, 2015), consolida-se a utilização de soluções químicas, tais como o silicato de sódio neutro, conforme já validado no estudo de Manoj-Prabahar et al., (2017).

Alghamri, Kanellopoulos e Al-Tabbaa (2016) apresentam duas formas de aplicação da solução de silicato no concreto, seriam elas por encapsulamento à vácuo e encapsulamento por submersão. Os autores ainda expõem bons resultados quanto a autocicatrização das fissuras em concretos com a presença da solução de silicato. Isso pois a reação do hidróxido de cálcio e do silicato de sódio, juntamente com a água, formam o gel de $\mathrm{C}-\mathrm{S}-\mathrm{H}$, produzindo cristais que contribuem no processo de cicatrização das fissuras. Analisaram microscopicamente (MEV) que os produtos formados foram etringita, portlandita e calcita.

Ainda, Alghamri, Kanellopoulos e Al-Tabbaa (2016), constatam maior ganho de resistência nas amostras com silicato de sódio, em uma mesma idade, pois ele proporcionou a formação de mais C-S-H. Tem-se assim o material como um agente promissor de cicatrização, justificando-se o desenvolvimento da presente pesquisa.

\section{ENCAPSULAMENTO DE SILICATO DE SÓdIO COMO AGENTE CICATRIZANTE}

Kanellopoulos, Qureshi e Al-Tabbaa (2015) trouxeram à tona o estudo com minerais encapsulados, os quais foram selecionados conforme a sua compatibilidade com a matriz cimentícia e seu baixo valor agregado. Em relação à tal técnica, Giannaros, Kanellopoulos e Al- 
Tabbaa (2016) pontuam que os encapsulamentos a base de sílica como agentes de cura, podendo ser silicato de sódio, são considerados excelentes para a autocicatrização de materiais cimentícios. Ainda, salientam que para a realização deste processo, o silicato de sódio reage com hidróxido de cálcio presente no cimento, e na presença de água irá formar um gel de hidrato de silicato de cálcio (C-S-H), originando o produto de hidratação do cimento.

Esta reação irá formar cristais que irão contribuir para a cicatrização das fissuras, fato que basicamente explica os bons resultados da pesquisa de Alghamri, Kanellopoulos e Al-Tabbaa (2016), quanto a autocicatrização das fissuras em concretos com a presença da solução de silicato, isto podendo acontecer por dois métodos de aplicação, por encapsulamento a vácuo e encapsulamento submerso. Estes autores observaram a formação de etringita, portlandita e calcita na área das fissuras, quando comparado o concreto convencional e o concreto com a solução de silicato de sódio, logo, evidenciaram que a solução possibilitou uma maior criação de gel C-S-H.

As soluções químicas ditas anteriormente são encapsuladas e inseridas na matriz, para proporcionar a autocicatrização e a autorregeneração, e posteriormente submetidas a tensões que levem a fissuração, o que tende a romper a capsula e consequentemente, liberar o agente regenerante (Gupta, Pang, Kua, 2017). Estes autores ainda afirmam que as fissuras em concretos com a solução de silicato de sódio neutro apresentam ganho de resistência estrutural aos 28 dias.

Todavia, é trazida em bibliografia a dificuldade de reprodução dos fenômenos de encapsulamento de agregados e se a sua viabilidade ocorrerá também em larga escala. Visando analisar diferentes estratégias de inserção do produto químico nos concretos, esse estudo avaliou a utilização de diferentes formas de silicato de sódio neutro em um mesmo traço de concreto, caracterizando os traços gerados e monitorando a cicatrização das fissuras.

\section{PROCEDIMENTO}

Para a análise dos diferentes métodos de utilização da solução de silicato de sódio neutro, contouse com a confecção de amostras prismáticas (6X6X18cm e $10 X 10 \mathrm{X} 30 \mathrm{~cm})$, as quais tiveram a formação de fissuras induzida pelo ensaio de tração na flexão NBR 12142 (ABNT, 2010) para acompanhamento da cicatrização. A Tabela 1 indica o traço utilizado. A solução de silicato utilizada neste estudo foi a de sódio neutro, dissolvida em 50\% agua deonizada. Os traços foram identificados da seguinte forma: PER.VAC: encapsulamento à vácuo em perlitas; PER.IMER: encapsulamento por imersão em perlitas; SIL.ÁGUA: adição do silicato de sódio na água de mistura; SIL.ASP: silicato de sódio aspergido após fissuração aos 7 dias.

Foram realizados ensaios aos 28 dias após moldagem, de resistência mecânica e índice de vazios. Para análise da cicatrização os materiais foram submetidos ao ensaio de tração na flexão, aos 7 dias, formando fissuras de $5 \mathrm{~mm}$.

Tabela 1 - Traço unitário para as soluções de concreto

\begin{tabular}{ccccccc}
\hline \multirow{2}{*}{ Nomenclatura } & \multicolumn{4}{c}{ Traço } & \multirow{2}{*}{$\begin{array}{c}\text { Concentração da Solução de } \\
\text { Silicato de Sódio Neutro }\end{array}$} \\
\cline { 2 - 5 } & Cimento & Areia & Perlita & Brita & a/c & 0,5 \\
\hline PER.VAC & 1 & 2,24 & 0,27 & 3,17 & 0,55 & 0,5 \\
\hline PER.IMER & 1 & 2,24 & 0,27 & 3,17 & 0,55 & 0,5 \\
\hline SIL.ÁGUA & 1 & 2,24 & 0,27 & 3,17 & 0,55 & 0,5 \\
\hline SIL.ASP & 1 & 2,24 & 0,27 & 3,17 & 0,55 & 0 \\
\hline REF (referência) & 1 & 2,24 & 0,27 & 3,17 & 0,55 &
\end{tabular}

\subsection{Materiais Utilizados}

Para a produção dos concretos foi utilizado em seu traço o cimento Portland (CP-II-F-40), por não conter adições pozolânicas. Para sua caracterização seguiu-se a NBR 16605 (ABNT, 2017), sendo que foi obtido o valor de $3,0049 \mathrm{~g} / \mathrm{cm}^{3}$. Como agregado miúdo utilizou-se areia média de origem quartzosa, caracterizada conforme a NBR NM 248 (ABNT, 2003). O módulo de finura foi 
de 1,62 e a dimensão máxima de 1,2mm. Ainda, para obtenção da massa específica e a determinação da massa unitária, utilizou-se a NBR NM 52 (ABNT, 2009), e a NBR NM 45 (ABNT, 2006), respectivamente. Os resultados foram de massa específica de $2,4948 \mathrm{~g} / \mathrm{cm}^{3} \mathrm{e}$ a massa unitária de 1,4921. Como agregado graúdo utilizou-se brita, de origem basálticas. Para a caracterização do tipo de brita escolhida, foi usada a NBR NM 248 (ABNT, 2003), já mencionada. Os resultados apontaram para um módulo de finura de 1,0915 e uma dimensão máxima de 12,5mm. A massa específica obtida foi de $2,7598 \mathrm{~g} / \mathrm{cm}^{3}$ e a massa unitária de $1,449 \mathrm{~g} / \mathrm{cm}^{3}$. Foi utilizada como agregado leve, para o encapsulamento da solução de silicato de sódio neutro, e/ou água, a perlita expandida, material fornecido diretamente pela Pervale, com dimensões entre 1,2 a 4,8 mm. A média da massa unitária da perlita é de $110,1 \mathrm{~kg} / \mathrm{m}^{3}$, conforme Pacheco (2020).

\subsection{Procedimentos}

\subsubsection{Preparo das amostras}

Salienta-se que a perlita para a PER.VAC e PER.IMER foram encapsuladas com a solução de silicato de sódio neutro. Enquanto a SIL.ÁGUA foi adicionada a perlita somente encapsulada com água, e adicionando a mistura a proporção de $50 \%$ de solução da água total da mistura, e por fim a SIL.ASP e REF, receberam somente a perlita encapsulada com água. Ainda no estado fresco, foi realizado o ensaio de determinação da consistência pelo abatimento de tronco de cone pela NBR 16889 (ABNT, 2020) obtendo-se valores entre a classe S160.

\subsubsection{Moldagem dos corpos de prova}

Os corpos de prova cilíndricos, para os ensaios de compressão e índices físicos foram moldados conforme a NBR 5738 (ABNT, 2018), sendo seis amostras por traço, três para cada idade, de 7 e 28 dias. As amostras para indução de fissuração e seu acompanhamento tiveram dimensões de 10 x 10 x 30cm (largura, altura, comprimento) e de 6x6x18cm, moldadas conforme a NBR 12142 (ABNT, 2010) e contendo uma barra de aço para resistir ao ensaio de tração sem rompimento frágil. A cura destes corpos de prova se deu por meio do método de cura úmida. Após o acompanhamento da cicatrização nas amostras prismáticas elas foram novamente submetidas aos ensaios mecânicos.

\subsubsection{Ensaios}

Foram realizados os ensaios de resistência à compressão conforme a norma NBR 5739 (ABNT, 2018). Para o ensaio de tração na flexão, a norma de referência foi a NBR 12142 (ABNT, 2010). Os índices físicos foram avaliados pela NBR 9778 (ABNT, 2009).

\subsubsection{Análise da autocicatrização com microscópio óptico}

Para a análise do processo de autocicatrização foi utilizado o microscópio óptico para visualização, no qual acoplou-se câmera de 12 megapixels. Estes registros foram realizados pós fissuração, data zero, e os demais capturados dez, onze, e dezenove dias após a data de fissuração.

\section{RESULTADOS}

\subsection{Resistência à compressão}

Os resultados obtidos estão dispostos na tabela 2.

Tabela 2 - Resultados ensaio de compressão uniaxial (7 e 28 dias)

\section{Resultados Ensaio de Compressão Uniaxial (7 e 28 dias)}

$$
7 \text { dias }
$$




\begin{tabular}{|c|c|c|c|c|c|c|c|}
\hline \multicolumn{2}{|l|}{$\begin{array}{l}\text { Corpo de } \\
\text { Prova }\end{array}$} & $\begin{array}{c}\text { Carga } \\
\text { Máxima } \\
(\mathrm{kN})\end{array}$ & $\begin{array}{c}\text { Tensão à } \\
\text { Compressão } \\
(\mathrm{MPa})\end{array}$ & $\begin{array}{c}\text { Valor médio } \\
\text { de tensão } \\
(\mathrm{MPa})\end{array}$ & $\begin{array}{l}\text { Carga } \\
\text { Máxima } \\
(\mathrm{kN})\end{array}$ & $\begin{array}{c}\text { Tensão à } \\
\text { Compressão } \\
(\mathrm{MPa})\end{array}$ & $\begin{array}{c}\text { Valor Médio } \\
\text { de tensão } \\
(\mathrm{MPa})\end{array}$ \\
\hline \multirow{3}{*}{ PER.VAC } & A & 242,78 & 30,9 & \multirow{3}{*}{29,8} & 283,9 & 35,7 & \multirow{3}{*}{35,9} \\
\hline & $\mathrm{B}$ & 240,6 & 30,3 & & 281,7 & 35,8 & \\
\hline & $\mathrm{C}$ & 221,27 & 28,3 & & 285,4 & 36,1 & \\
\hline \multirow{3}{*}{ PER.IMER } & $\mathrm{A}$ & 208,4 & 26,4 & \multirow{3}{*}{27,0} & 232,6 & 29,7 & \multirow{3}{*}{30,0} \\
\hline & $\mathrm{B}$ & 212,73 & 27,1 & & 235,7 & 30,2 & \\
\hline & $\mathrm{C}$ & 216,14 & 27,4 & & 234,6 & 30 & \\
\hline \multirow{3}{*}{ SIL.AGUA } & $\mathrm{A}$ & 98,37 & 12,5 & \multirow{3}{*}{14,9} & 171,1 & 21,8 & \multirow{3}{*}{17,5} \\
\hline & $\mathrm{B}$ & 139,8 & 17,8 & & 103,7 & 13,2 & \\
\hline & $\mathrm{C}$ & 112,35 & 14,3 & & 137,8 & 17,6 & \\
\hline \multirow{3}{*}{ SIL.ASP } & A & 200,57 & 25,5 & \multirow{3}{*}{25,5} & 221 & 28,4 & \multirow{3}{*}{29,8} \\
\hline & $\mathrm{B}$ & 195,42 & 25 & & 242,3 & 30,7 & \\
\hline & $\mathrm{C}$ & 204,16 & 26 & & 236,9 & 30,2 & \\
\hline \multirow{3}{*}{ REF } & A & 205,26 & 26 & \multirow{3}{*}{26,2} & 243,5 & 30,9 & \multirow{3}{*}{30,7} \\
\hline & $\mathrm{B}$ & 210,12 & 26,8 & & 240,6 & 30,5 & \\
\hline & $\mathrm{C}$ & 203,22 & 25,8 & & 241,9 & 30,7 & \\
\hline
\end{tabular}

Todos os traços apresentaram a relação esperada de ganho de resistência proporcional ao tempo de cura do concreto (Mehta; Monteiro, 2014), sendo a amostra PER.VAC a que obteve a maior porcentagem de ganho de resistência de 7 dias para 28 dias. Quanto a maior resistência de cada amostra, todas, exceto a SIL.ÁGUA, apresentaram resultados próximos, devido ao fato de serem compostas pelo mesmo material, composição e condições de preparo.

Contudo, como mencionado anteriormente, uma das soluções, a SIL.ÁGUA, embora tenha apresentado um ganho de resistência proporcional ao tempo de cura, apresentou valores, quanto a resistência, significativamente menores, cerca de $80 \%$ a menos, o que se explica pelo fato de que esta amostra possui uma adição da solução de silicato de sódio neutro direto na mistura, propiciando um concreto com rápida pega inicial, e elevado ganho de vazios no processo de moldagem. Essa pega inicial é citada por Provis e Van Deventer (2014) que informam que o produto é um ativador alcalino. o silicato de sódio é utilizado como aditivo do concreto para acelerar a pega.

Essa maior formação de vazios na amostra impactou na resistência mecânica, e assim, mesmo com um processo mais passível de reprodução em larga escala, não obteve-se comportamento mecânico satisfatório. Em relação aos diferentes tratamentos para encapsulamento das perlitas, notou-se que em ambas as idades a resistência foi superior nas amostras com a utilização de vácuo, comportamento contrário ao obtido por Pacheco (2020) utilizando-se o mesmo produto de cicatrização. Ainda, é pertinente destacar um comportamento já esperado, de semelhança entre as amostras SIL.ASP e REF, por conterem a mesma composição, sem alterações nas amostras, sendo essas feitas apenas após a formação de fissuras.

4.2 Resistência à tração na flexão 


\subsubsection{Resultados de resistência à tração na flexão CP's - $6 \mathrm{~cm} \times 6 \mathrm{~cm} \times 18 \mathrm{~cm}$ (7 e 28 dias)}

Os resultados obtidos para o ensaio de resistência à tração na flexão para os CP's de $6 \mathrm{~cm}$ x $6 \mathrm{~cm}$ x $18 \mathrm{~cm}$, estão dispostos na tabela 3 , e complementados pela figura 1:

Tabela 1 - Resultados tração na flexão (CP's - $6 \mathrm{~cm}$ x $6 \mathrm{~cm}$ x $18 \mathrm{~cm})(7$ e 28 dias)

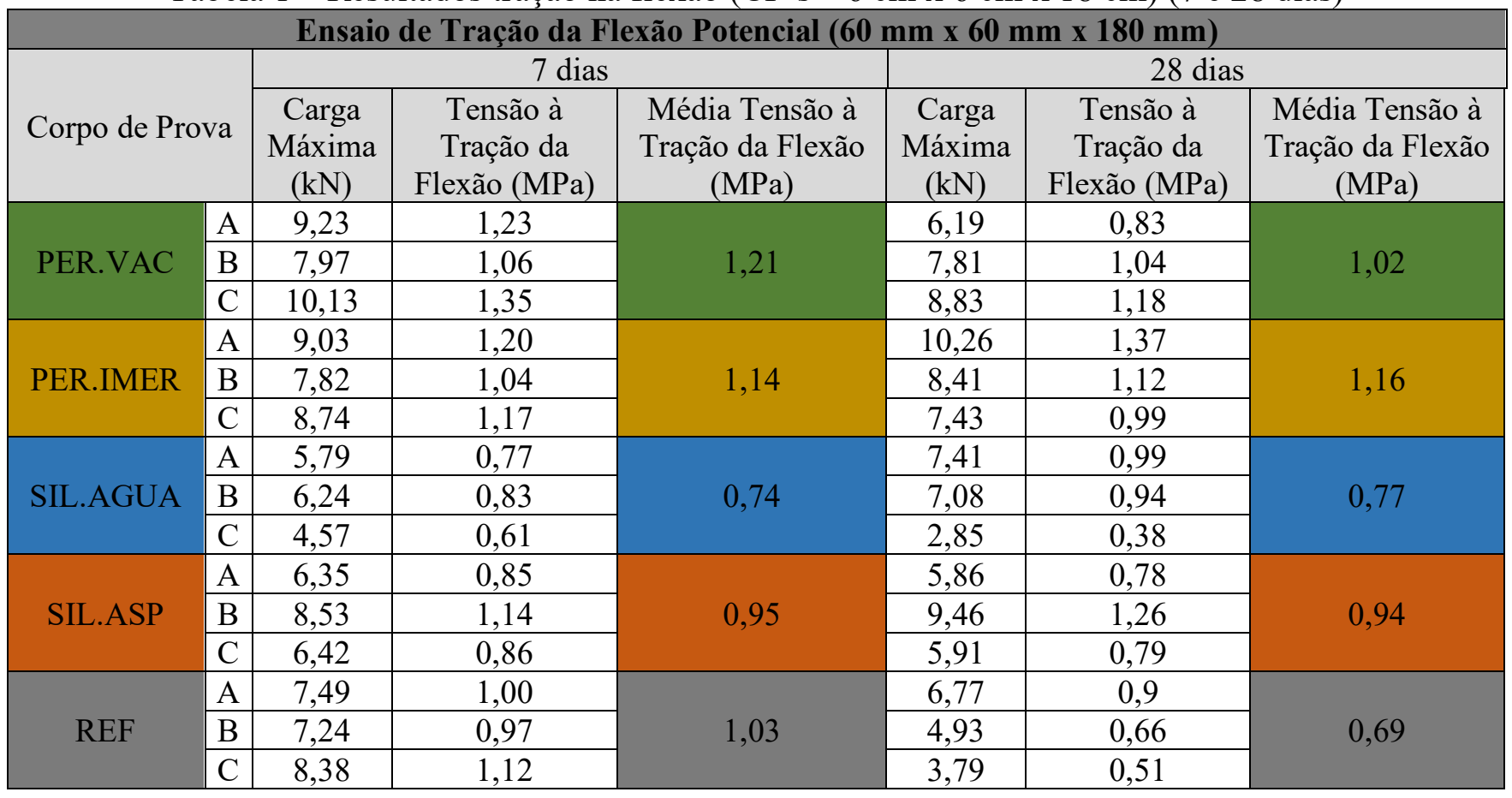

Figura 1- Gráfico comparativo tensão média tração na flexão (CP's - $6 \mathrm{~cm} \times 6 \mathrm{~cm} \times 18 \mathrm{~cm})(7 \mathrm{e}$ 28 dias)

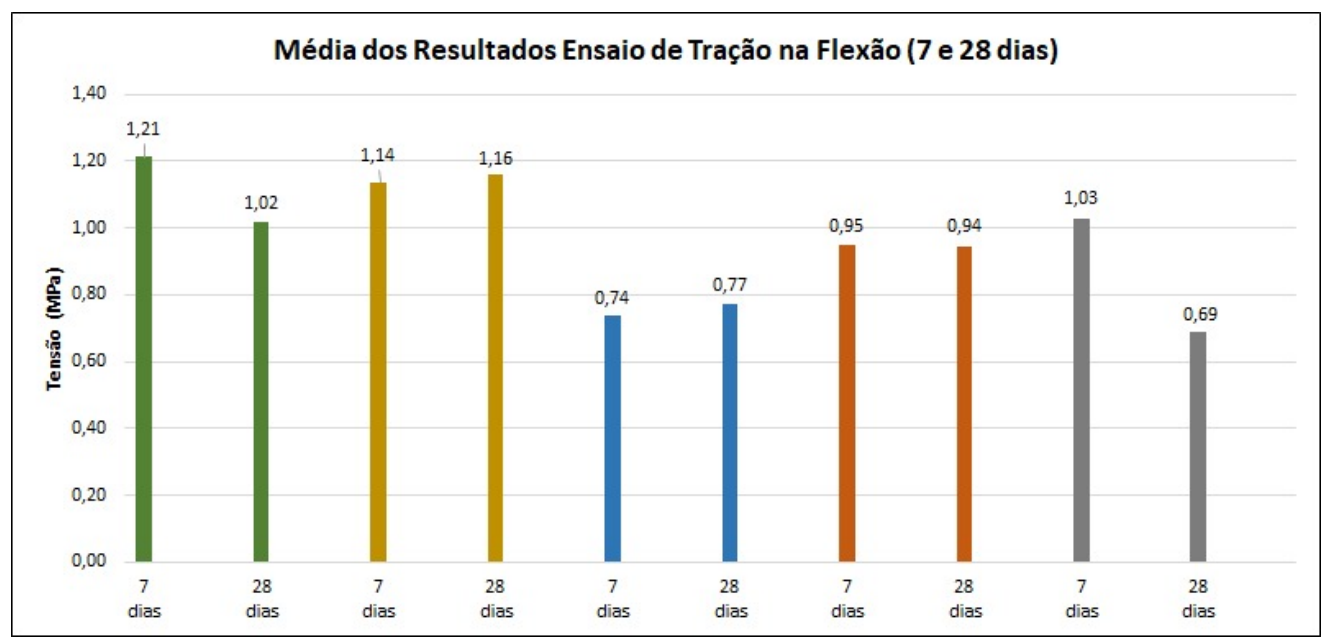

\section{2 .2 Resultados do ensaio de resistência à tração na flexão CP's $-10 \mathrm{~cm} \times 10 \mathrm{~cm} \times 30 \mathrm{~cm}(7 \mathrm{e}$ 28 dias)}

Os resultados obtidos para o ensaio de resistência à tração na flexão para os CP's de 10 cm x 10 cm x $30 \mathrm{~cm}$, estão dispostos na tabela 4, e complementados pela figura 2.

Tabela 2 - Resultados tração na flexão (CP's - $10 \mathrm{~cm}$ x $10 \mathrm{~cm}$ x $30 \mathrm{~cm}$ ) (7 e 28 dias) 


\begin{tabular}{|c|c|c|c|c|c|c|c|}
\hline \multicolumn{8}{|c|}{ Ensaio de Tração da Flexão Potencial (100 mm x 100 mm x 300 mm) } \\
\hline \multirow{2}{*}{\multicolumn{2}{|c|}{ Corpo de Prova }} & \multicolumn{3}{|c|}{7 dias } & \multicolumn{3}{|c|}{28 dias } \\
\hline & & $\begin{array}{l}\text { Carga } \\
\text { Máxima } \\
(\mathrm{kN})\end{array}$ & $\begin{array}{l}\text { Tensão à } \\
\text { Tração da } \\
\text { Flexão } \\
\text { (MPa) }\end{array}$ & $\begin{array}{l}\text { Média Tensão à } \\
\text { Tração da Flexão } \\
(\mathrm{MPa})\end{array}$ & $\begin{array}{l}\text { Carga } \\
\text { Máxima } \\
(\mathrm{kN})\end{array}$ & $\begin{array}{l}\text { Tensão à } \\
\text { Tração da } \\
\text { Flexão } \\
(\mathrm{MPa})\end{array}$ & $\begin{array}{l}\text { Média Tensão à } \\
\text { Tração da Flexão } \\
(\mathrm{MPa})\end{array}$ \\
\hline \multirow{3}{*}{ PER.VAC } & A & 16,73 & 2,23 & \multirow{3}{*}{2,39} & 23,13 & 3,08 & \multirow{3}{*}{3,10} \\
\hline & $\mathrm{B}$ & 17,47 & 2,33 & & 23,76 & 3,17 & \\
\hline & $\mathrm{C}$ & 19,59 & 2,61 & & 22,79 & 3,04 & \\
\hline \multirow{3}{*}{ PER.IMER } & $\mathrm{A}$ & 15,41 & 2,05 & \multirow{3}{*}{2,50} & 16,52 & 2,2 & \multirow{3}{*}{2,54} \\
\hline & $\mathrm{B}$ & 20,13 & 2,68 & & 20,92 & 2,79 & \\
\hline & $\mathrm{C}$ & 20,74 & 2,77 & & 19,62 & 2,62 & \\
\hline \multirow{3}{*}{ SIL.AGUA } & $\mathrm{A}$ & 11,79 & 1,57 & \multirow{3}{*}{1,70} & 12,85 & 1,71 & \multirow{3}{*}{1,83} \\
\hline & $\mathrm{B}$ & 14,13 & 1,88 & & 15,64 & 2,09 & \\
\hline & $\mathrm{C}$ & 12,46 & 1,66 & & 12,76 & 1,7 & \\
\hline \multirow{3}{*}{ SIL.ASP } & A & 22,16 & 2,95 & \multirow{3}{*}{2,73} & 26,19 & 3,49 & \multirow{3}{*}{2,92} \\
\hline & $\mathrm{B}$ & 16,99 & 2,26 & & 14,84 & 1,98 & \\
\hline & $\mathrm{C}$ & 22,27 & 2,97 & & 24,58 & 3,28 & \\
\hline \multirow{3}{*}{ REF } & $\mathrm{A}$ & 18,66 & 2,49 & \multirow{3}{*}{2,60} & 19,35 & 2,58 & \multirow{3}{*}{2,72} \\
\hline & $\mathrm{B}$ & 20,45 & 2,73 & & 20,67 & 2,76 & \\
\hline & $\mathrm{C}$ & 19,45 & 2,59 & & 21,05 & 2,81 & \\
\hline
\end{tabular}

Figura 2 - Gráfico comparativo tensão média tração na flexão (CP's $-10 \mathrm{~cm} \times 10 \mathrm{~cm} \times 30 \mathrm{~cm})$ (7 e 28 dias)

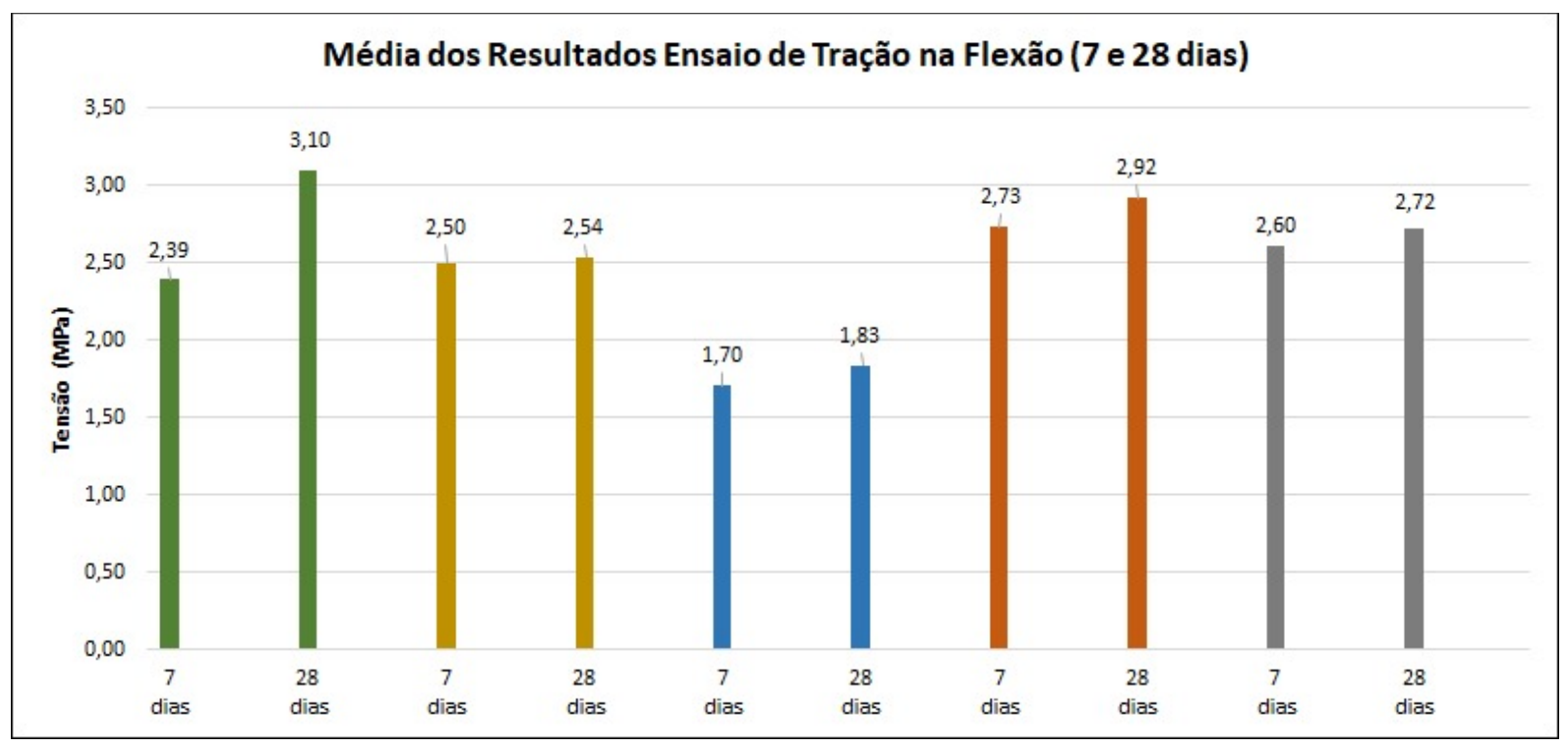

Para este ensaio foram desenvolvidos CP's com diferentes dimensões, como já mencionado anteriormente, sendo elas de $6 \mathrm{~cm}$ × $6 \mathrm{~cm} \times 18 \mathrm{~cm}$, e $10 \mathrm{~cm}$ x $10 \mathrm{~cm} \times 30 \mathrm{~cm}$, todas levadas a cargas distintas para que se obtivesse, aos 7 dias, fissuras com $5 \mathrm{~mm}$ de espessura. Portando, já aos 7 dias foi possível observar que mesmo que o concreto seja um material uniforme, e executado neste caso em uma mesma concretagem, os corpos de prova necessitaram cargas diferentes para obtenção da mesma abertura de fissuras. Entretanto, como foi possível observar nos gráficos, por se tratar de um concreto armado, os elementos obtiveram dois ganhos de resistência, o primeiro, a faixa onde o concreto está atuando, e posteriormente, o rompimento do mesmo, onde se observou o ganho de resistência quando a carga começou a atuar no conjunto com a armadura do corpo de prova. Mehta e Monteiro (2014) demonstram as diferenças dos módulos de elasticidade de concretos 
convencionais e concretos armados, vistas nos gráficos pelo desenvolvimento das retas e curvas apresentadas.

Já o ensaio aos 28 dias dos mesmos corpos de prova, os quais continham a adição da solução de silicato de sódio neutro, PER.VAC, PER.IMER, SIL.ÁGUA e SIL.ASP, permitiram analisar que, não houve somente a autocicatrização, mas também a autorregeneração, fazendo com que o concreto ganhe resistência após o processo de fissuração inicial. Esse fenômeno foi abordado na pesquisa de Alghami, Kanellopoulos e Al-Tabbaa (2016), que demonstrou o processo utilizando o encapsulamento de silicato de sódio em agregados leves. Ainda sobre este assunto, a pesquisa realizada por Gupta, Pang e Kua (2017), informa que as fissuras são capazes de romper o encapsulamento liberando o agente reagente, e consequentemente, evidenciando a recuperação das fissuras, já aos 28 dias. Diferentemente das amostras da REF, qual não receberam qualquer tipo de solução, e, portanto, não obtiveram ganho de resistência.

Ainda referente ao processo de autoregeneração, avaliado a partir deste ensaio, qual é responsável por fornecer valores quanto as propriedades mecânicas (resistência à tração na flexão), foi possível observar que a PER.VAC obteve os melhores resultados quanto ao ganho de resistência pós fissuração aos 7 dias, diferença vista na Figura 3.

Figura 3 - Gráfico comparativo melhor resultado ganho de resistência de tração na flexão PER.VAC (CP's - $10 \mathrm{~cm} \times 10 \mathrm{~cm}$ x $30 \mathrm{~cm}$ ) (7 e 28 dias)

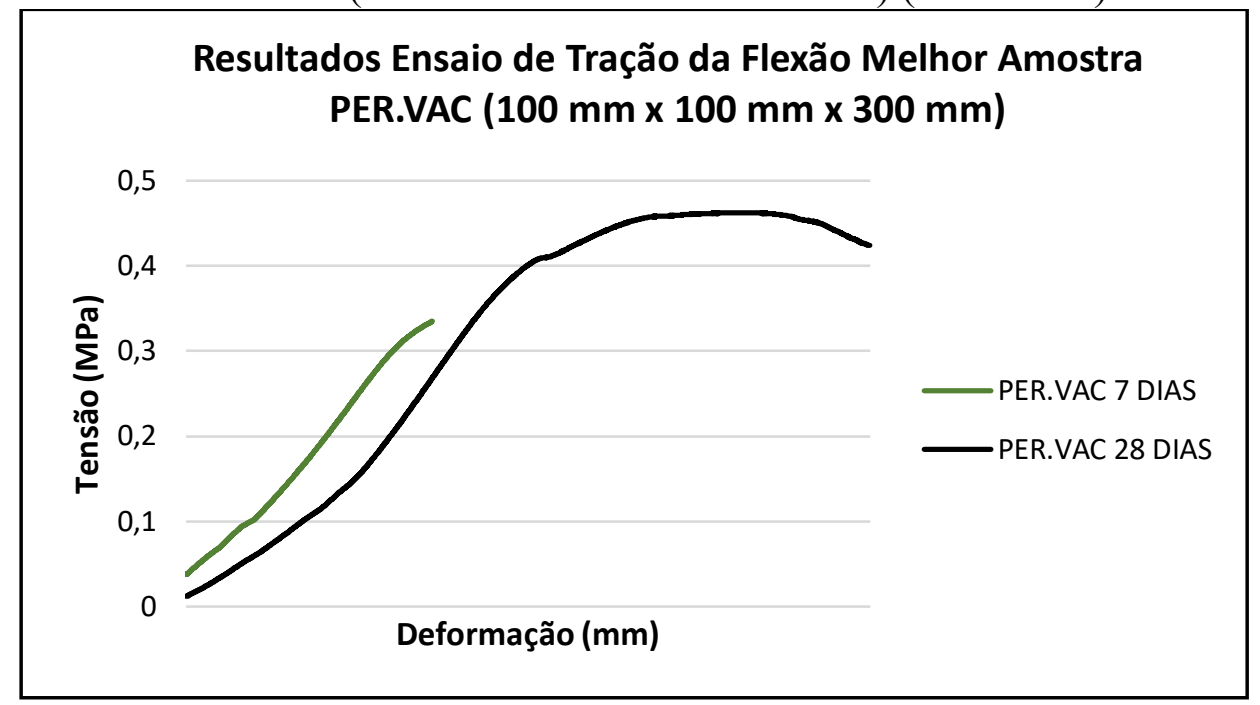

Fonte: Autor (2020

Referente a resistência a tração na flexão, analisada no item atual, a mesma também obteve resultados consideráveis pois como mostram os comparativos ela apresentou um ganho de resistência, tanto aos 7 dias quanto aos 28 dias em seus CP's. Assim, vale salientar que embora os seus resultados tenham dados inferiores se comparado as demais soluções, caso haja uma correção em seu traço para obter mais resistência, pode ser considerado um concreto autorregenerantes e autocicatrizante. Referente a adição da solução diretamente sobre a superfície, Medeiros, Pereira e Helene (2012), trazem à tona a sua efetividade quanto a sua proteção e durabilidade, aumentando a vida útil da estrutura. As análises destes resultados estão dispostas nas tabelas 3 e 4.

Tabela 3 - Ganho de resistência após o período de autorregeneração ensaio de tração na flexão melhores amostras $6 \mathrm{~cm} \times 6 \mathrm{~cm} \times 18 \mathrm{~cm}$ (7 e 28 dias)

Ensaio de Tração da Flexão Potencial $(60 \mathrm{~mm}$ x $60 \mathrm{~mm}$ x $180 \mathrm{~mm})$ 


\begin{tabular}{|c|c|c|c|c|c|}
\multirow{2}{*}{ Corpo de Prova } & \multicolumn{2}{|c|}{7 dias } & \multicolumn{2}{|c|}{28 dias } & Porcentagem \\
\cline { 2 - 5 } & $\begin{array}{c}\text { Carga } \\
\text { Máxima } \\
(\mathrm{kN})\end{array}$ & $\begin{array}{c}\text { Tensão à Tração } \\
\text { da Flexão }(\mathrm{MPa})\end{array}$ & $\begin{array}{c}\text { Carga } \\
\text { Máxima } \\
(\mathrm{kN})\end{array}$ & $\begin{array}{c}\text { Tensão à Tração } \\
\text { da Flexão (MPa) }\end{array}$ & $\begin{array}{c}\text { Ganho de } \\
\text { Resistência (\%) }\end{array}$ \\
\hline PER.VAC - B & 7,97 & 1,06 & 7,81 & 1,04 & $-2 \%$ \\
\hline PER.IMER - A & 9,03 & 1,20 & 10,26 & 1,37 & $14 \%$ \\
\hline SIL.AGUA - A & 5,79 & 0,77 & 7,41 & 0,99 & $29 \%$ \\
\hline SIL.ASP - B & 8,53 & 1,14 & 9,46 & 1,26 & $11 \%$ \\
\hline REF - A & 7,49 & 1,00 & 6,77 & 0,9 & $-10 \%$ \\
\hline
\end{tabular}

Tabela 4 - Ganho de resistência após o período de autorregeneração ensaio de tração na flexão melhores amostras $10 \mathrm{~cm} \times 10 \mathrm{~cm} \times 30 \mathrm{~cm}$ (7 e 28 dias)

\begin{tabular}{|c|c|c|c|c|c|}
\hline \multirow{2}{*}{ Ensaio de Tração da Flexão Potencial (100 mm x $\mathbf{1 0 0} \mathbf{~ m m} \times \mathbf{3 0 0} \mathbf{~ m m})$} \\
\cline { 2 - 5 } Corpo de Prova & $\begin{array}{c}\text { Carga } \\
\text { Máxima } \\
(\mathrm{kN})\end{array}$ & $\begin{array}{c}\text { Tensão à } \\
\text { Tração da } \\
\text { Flexão (MPa) }\end{array}$ & $\begin{array}{c}\text { Carga } \\
\text { Máxima } \\
(\mathrm{kN})\end{array}$ & $\begin{array}{c}\text { Tensão à } \\
\text { Tração da } \\
\text { Flexão (MPa) }\end{array}$ & $\begin{array}{c}\text { Porcentagem } \\
\text { Ganho de } \\
\text { Resistência (\%) }\end{array}$ \\
\hline PER.VAC - A & 16,73 & 2,23 & 23,13 & 3,08 & $38 \%$ \\
\hline PER.IMER - A & 15,41 & 2,05 & 16,52 & 2,2 & $7 \%$ \\
\hline SIL.AGUA - B & 14,13 & 1,88 & 15,64 & 2,09 & $11 \%$ \\
\hline SIL.ASP - A & 22,16 & 2,95 & 26,19 & 3,49 & $18 \%$ \\
\hline REF - C & 19,45 & 2,59 & 21,05 & 2,81 & $8 \%$ \\
\hline
\end{tabular}

Como pode ser percebido, não houve um comportamento igual nas duas geometrias de amostra. Enquanto que nas amostras de menor dimensão o traço mais bem sucedido foi o que incorpou a solução na água de amassamento, nas maiores amostras o traço com maior ganho de resistência foi o com encapsulamento com aplicação de vácuo.

A maior resistência aos 28 dias pode ser oriunda das reações de hidratação do silicato (no caso do inserido na água de amassamento), ou pela formação de produtos de cicatrização, que possam ter atuado provocando melhorias em seu comportamento mecânico.

\subsection{Determinação da absorção e índice de vazios}

\subsubsection{Resultados do ensaio de absorção e índice de vazios (28 dias)}

Os resultados obtidos estão dispostos na tabela 5.

Para essa análise, cabe destacar que todos os traços contaram com perlita em sua composição, sem ser esse o efeito predominante no que tange a maior presença de vazios entre um traço e outro (Sengul et al, 2011). Percebeu-se que o maior índice de vazios foi atribuído ao traço no qual a solução de silicato ocorreu na água de amassamento, aspecto percebido durante a moldagem, quando a mistura se apresentou menos coesa. Entre os diferentes procedimentos de encapsulamento, foram notadas sutis alterações, tanto na absorção de água quanto no índice de vazios. Tais alterações podem decorrer também da distribuição das perlitas ao longo da matriz. Esses resultados de encapsulamento apresentaram resultado semelhante ao traço de referência.

Tabela 5 - Resultados ensaio de absorção e índice de vazios (28 dias)

\section{Resultados Ensaio de Absorção (28 dias)}




\begin{tabular}{|c|c|c|c|c|c|c|}
\hline \multicolumn{2}{|c|}{ Corpo de Prova } & $\begin{array}{c}\text { Média - Msat } \\
\text { (g) }\end{array}$ & $\begin{array}{l}\text { Média - Mi } \\
\text { (g) }\end{array}$ & $\begin{array}{l}\text { Média - } \\
\text { Ms (g) }\end{array}$ & $\begin{array}{l}\text { Absorção de Água por } \\
\text { Imersão }(\%)\end{array}$ & $\begin{array}{l}\text { Índice de } \\
\text { Vazios (\%) }\end{array}$ \\
\hline \multirow{3}{*}{ PER.VAC } & A & \multirow{3}{*}{3638,8} & \multirow{3}{*}{2072,8} & \multirow{3}{*}{3354,7} & \multirow{3}{*}{$8,47 \%$} & \multirow{3}{*}{$18,14 \%$} \\
\hline & $\mathrm{B}$ & & & & & \\
\hline & $\mathrm{C}$ & & & & & \\
\hline \multirow{3}{*}{ PER.IMER } & $\mathrm{A}$ & \multirow{3}{*}{3636,5} & \multirow{3}{*}{2068,6} & \multirow{3}{*}{3340,3} & \multirow{3}{*}{$8,87 \%$} & \multirow{3}{*}{$18,89 \%$} \\
\hline & $\mathrm{B}$ & & & & & \\
\hline & $\mathrm{C}$ & & & & & \\
\hline \multirow{3}{*}{ SIL.AGUA } & $\mathrm{A}$ & \multirow{3}{*}{3002,2} & \multirow{3}{*}{1653,3} & \multirow{3}{*}{2681,5} & \multirow{3}{*}{$11,96 \%$} & \multirow{3}{*}{$23,77 \%$} \\
\hline & B & & & & & \\
\hline & $\mathrm{C}$ & & & & & \\
\hline \multirow{3}{*}{ SIL.ASP } & $\mathrm{A}$ & \multirow{3}{*}{3648,4} & \multirow{3}{*}{2074,2} & \multirow{3}{*}{3328,6} & \multirow{3}{*}{$9,61 \%$} & \multirow{3}{*}{$20,31 \%$} \\
\hline & $\mathrm{B}$ & & & & & \\
\hline & $\mathrm{C}$ & & & & & \\
\hline \multirow{3}{*}{$\mathrm{REF}$} & A & \multirow{3}{*}{3648,3} & \multirow{3}{*}{2076,2} & \multirow{3}{*}{3354,8} & \multirow{3}{*}{$8,75 \%$} & \multirow{3}{*}{$18,67 \%$} \\
\hline & $\mathrm{B}$ & & & & & \\
\hline & $\mathrm{C}$ & & & & & \\
\hline
\end{tabular}

\subsection{Análise e discussão da autocicatrização das fissuras}

A partir das análises desenvolvidas, com o auxílio de microscópio, foi possível observar que todos os elementos que continham a solução em sua composição, apresentaram o processo de autocicatrização. Vale ressaltar que até mesmo a SIL.ASP, com a solução inserida externamente obteve sucesso neste processo. Como já abordado anteriormente, pesquisas como a de Medeiros, Pereira e Helene (2012), mostram que a aspersão direto sobre a superfície ocasiona o fechamento dos poros após reação do silicato de sódio $\left(\mathrm{Na}_{2} \mathrm{SiO}_{3}\right)$ com o $\mathrm{NaOH}$. Ainda sobre os demais métodos de aplicação do silicato, como o encapsulamento da solução, Alghamri, Kanellopoulos e Al-Tabbaa (2016), evidenciam o processo de autocicatrização através da adição de agregados leves.

Há indícios de que a permanência em câmara de cura, e com submersão das amostras tenha beneficiado o processo de autocicatrização Quanto as dimensões máximas das fissuras existentes nas amostras, todas obtiveram espessuras iniciais de $5 \mathrm{~mm}$ após retirada da carga aos 7 dias, medida conferida com o auxílio de fissurômetro. A análise foi realizada conforme as imagens a seguir:

\subsubsection{Imagens autocicatrização PER.VAC}

A Figura 4 apresenta o comportamento das amostras nas quais o silicato de sódio foi impregnado nas perlitas com a utilização de câmara de vácuo.

Figura 4 - Amostras $10 \mathrm{~cm}$ x $10 \mathrm{~cm}$ x $30 \mathrm{~cm}$ PER.VAC -Zoom 30x (dia 19)
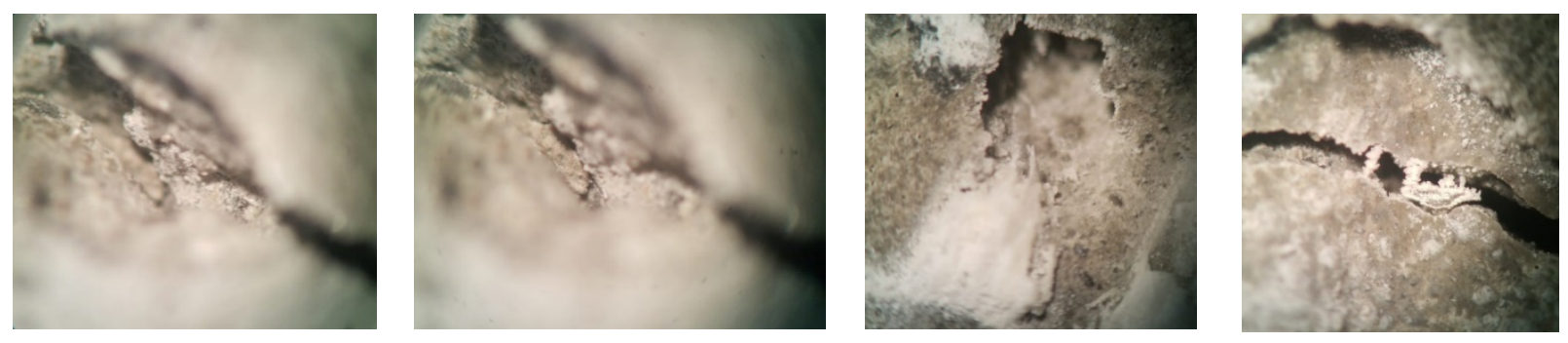

Como é possível perceber, nas perlitas encapsuladas à vácuo, houve pequena participação da cicatrização, se manifestando principalmente com formação dos produtos na borda, sem a 
efetivação da cicatrização total, ou contínua, como classificado por Pacheco (2020). Porém, vale salientar que como observado nos ensaios de resistência à tração na flexão, esta solução foi a que apresentou melhores resultados, quais apareceram também na pesquisa de Alghamri, Kanellopoulos e Al-Tabbaa (2016), que utilizaram também agregados leves.

Ainda pode-se observar que o processo de fissuração acaba promovendo o rompimento das cápsulas, assim liberando o agente regenerante, conforme pesquisa realizada por Gupta, Pang e Kua (2017). Estes autores destacam que já é possível evidenciar recuperação da estrutura aos 28 dias, resultado também apresentado para esta solução nesta pesquisa.

\subsubsection{Imagens autocicatrização PER.IMER}

A Figura 5 apresenta as ocorrências de cicatrização nas amostras com impregnação de silicato de sódio por imersão nas perlitas.

Figura 5-Amostras $10 \mathrm{~cm} \times 10 \mathrm{~cm} \times 30 \mathrm{~cm}$ PER.IMER-A-Zoom 30x (dia 19)
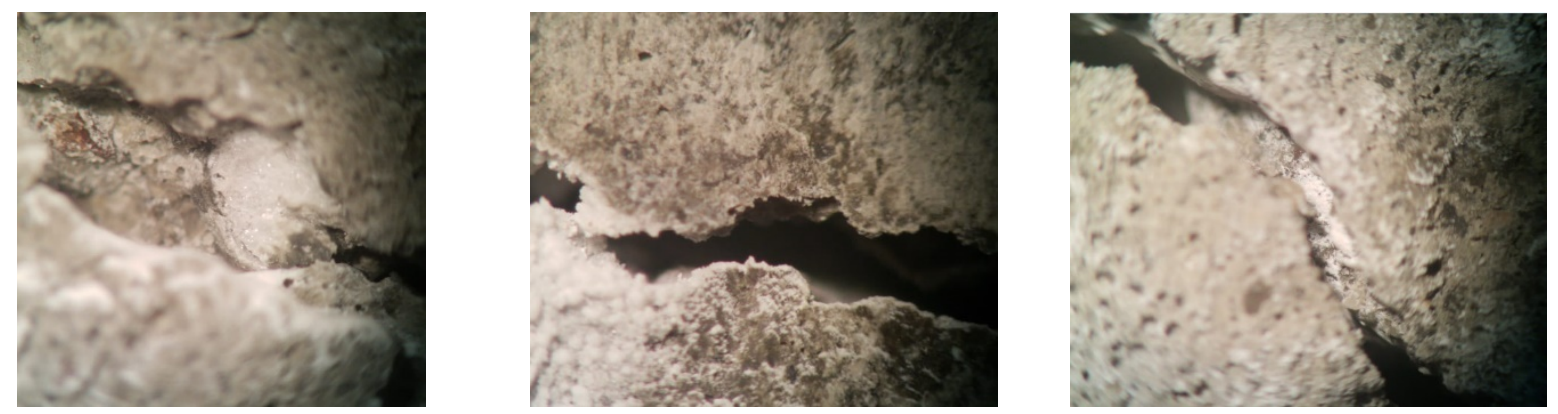

Novamente, nota-se que com o tratamento de impregnação por imersão das perlitas não houve formação considerável de produto de cicatrização. O fato da ocorrência ter sido pontual, pode decorrer da disponibilidade de perlita no local onde houve a formação da fissura (Wu et al, 2012). Autores como Alghamri, Kanellopoulos e Al-Tabbaa (2016), mostram em suas pesquisas que apesar da simples imersão das perlitas em solução ter efetividade, acabam por não apresentar grandes evoluções quanto a autoregeneração, resultado complementado e evidenciado pelo ensaio de resistênca à tração na flexão, onde o PER.IMER não obteve grandes resultados.

\subsubsection{Imagens autocicatrização SIL.AGUA}

Dando continuidade a apresentação dos resultados, a Figura 6 apresenta as amostras nas quais o silicato de sódio foi inserido na mistura pela água de amassamento.

Figura 6-Amostras $10 \mathrm{~cm} \times 10 \mathrm{~cm} \times 30 \mathrm{~cm}$ SIL.AGGA - C-Zoom 3000x (dia 19)

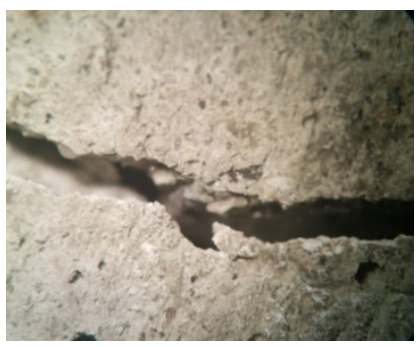

A dispersão da solução de silicato de sódio na água de amassamento parece ter sido ineficaz para o processo de autocicatrização, uma vez que não foram percebidos produtos nem pontualmente. Cabe lembrar, aqui, o comportamento desse material em termos de resistência à compressão, na qual notou-se uma evolução quanto ao ganho de resistência durante o período de 
cura do concreto, porém como evidenciado neste mesmo ensaio, a SIL.ÁGUA teve resultados significativamente menores, do que as demais soluções, visto que possibilitou maior índice de vazios e maior dificuldade quanto ao processo de adensamento e moldagem. Importante salientar que soluções como a de silicato de sódio são adicionadas ao concreto como aditivos aceleradores do processo de endurecimento, como mencionado por Mehta e Monteiro (2014).

\subsubsection{Imagens autocicatrização SIL.ASP}

As Figuras 7,8,9 e 10 apresentam as ocorrências nas amostras que contarão com aspersão de silicato de sódio diretamente nas fissuras.

Figura 7 -Amostras $10 \mathrm{~cm} \times 10 \mathrm{~cm} \times 30 \mathrm{~cm}$ SIL.ASP - C-Zoom 3000x (dia 10)

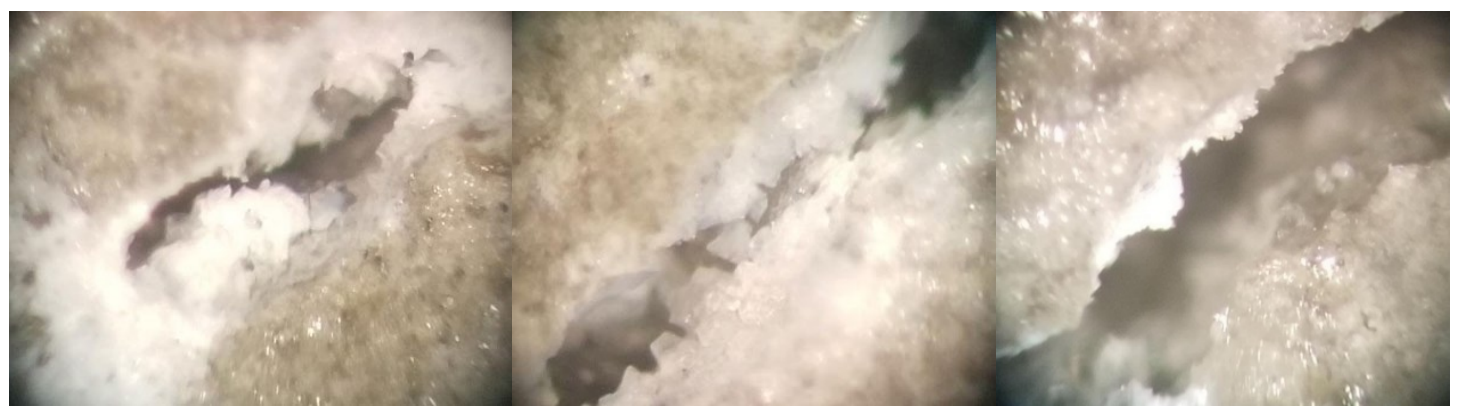

Figura 8-Amostras $10 \mathrm{~cm} \times 10 \mathrm{~cm} \times 30 \mathrm{~cm}$ SIL.ASP-C e A (dia 10)
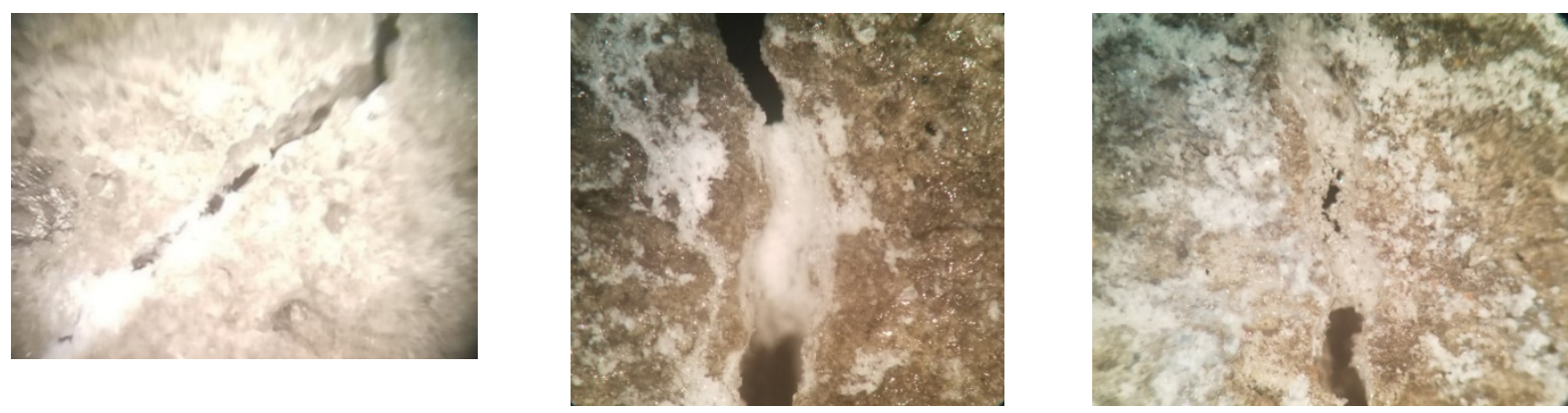

Figura 9-Amostras $6 \mathrm{~cm} \times 6 \mathrm{~cm} \times 6 \mathrm{~cm}$ SIL.ASP-B-Zoom 7,5x (dia 11)

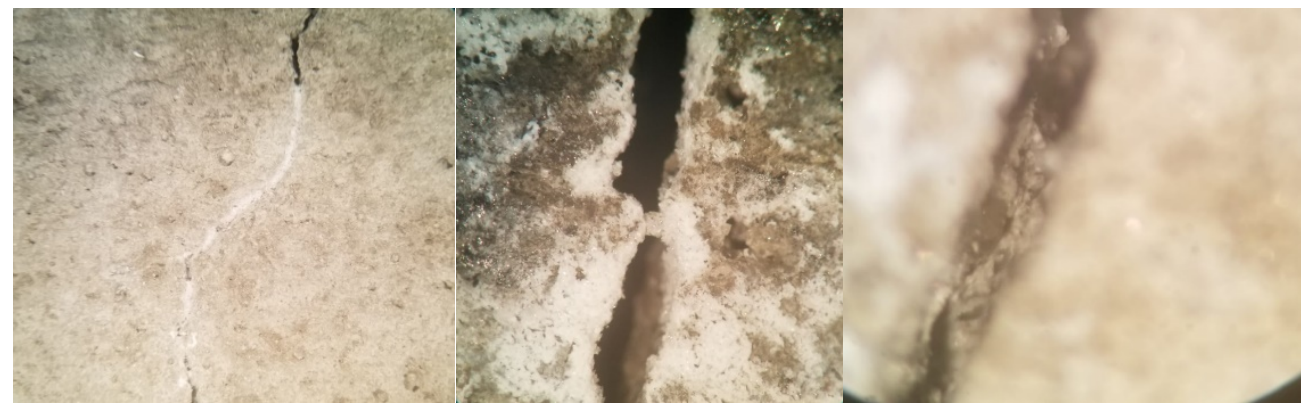


Figura 10 -Amostras $10 \mathrm{~cm} \times 10 \mathrm{~cm} \times 30 \mathrm{~cm}$ SIL.ASP - A - Zoom 7,5x (dia 19) e SIL.ASP - C Zoom 30x (dia 19)
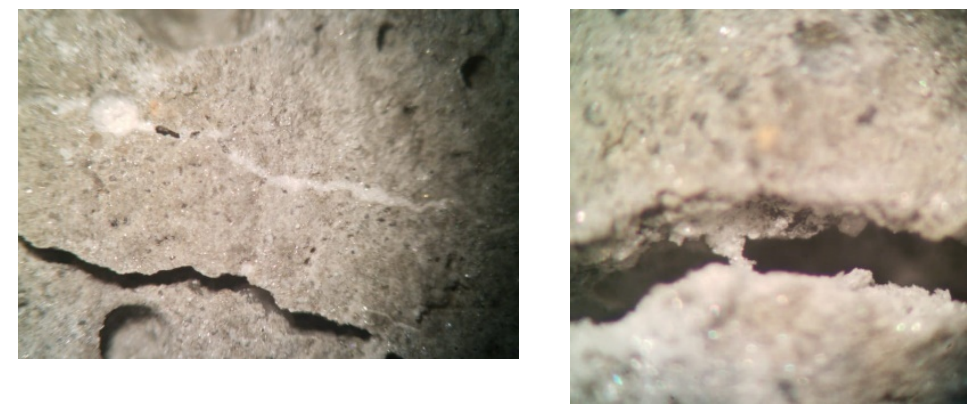

Como é possível aferir pelas imagens supraapresentadas, a aspersão do silicato diretamente no local onde as fissuras ocorrem efetivou mais ocorrências de cicatrização. Como demonstra a Figura acima, chegou a ocorrer um trecho de cicatrização continua ao longo de uma fissura. Além disso, elimina-se a necessidade de disposição da perlita no local para que ocorra o fenômeno, e assim, foram percebidos mais pontos de cicatrização pontual. A aspersão do silicato mostrou-se não somente eficaz quanto ao processo de cicatrização, mas também evidenciou ganhos na propriedade mecânica do concreto, isto apresentado pelo ensaio de resistência à tração na flexão. Outro adendo a ser levado em consideração para este método, é o de que trata-se de um procedimento que pode ocorrer pós aparecimento das fissuras diferentemente dos demais que devem ser previstos no momento da concretagem.Estudos como o de Medeiros, Pereira e Helene (2012), mostram que o $\mathrm{Na}_{2} \mathrm{SiO}_{3}$ quando em contato com o $\mathrm{NaOH}$, promove a formação de gel de silicato de cálcio hidratado responsável por fechar as fissuras e tornar o elemento pouco permeável, assim aumentando a vida útil da estrutura, e não proporcionando o possível ataque de cloretos.

\subsubsection{Imagens autocicatrização REF}

Por fim, a Figura 11 apresenta amostras do concreto considerado como referência, que não apresentaram nesse estudo nenhuma ocorrência de cicatrização.

Figura 11 -Amostras $6 \mathrm{~cm} \times 6 \mathrm{~cm} \times 18 \mathrm{~cm}$ REF (dia zero)

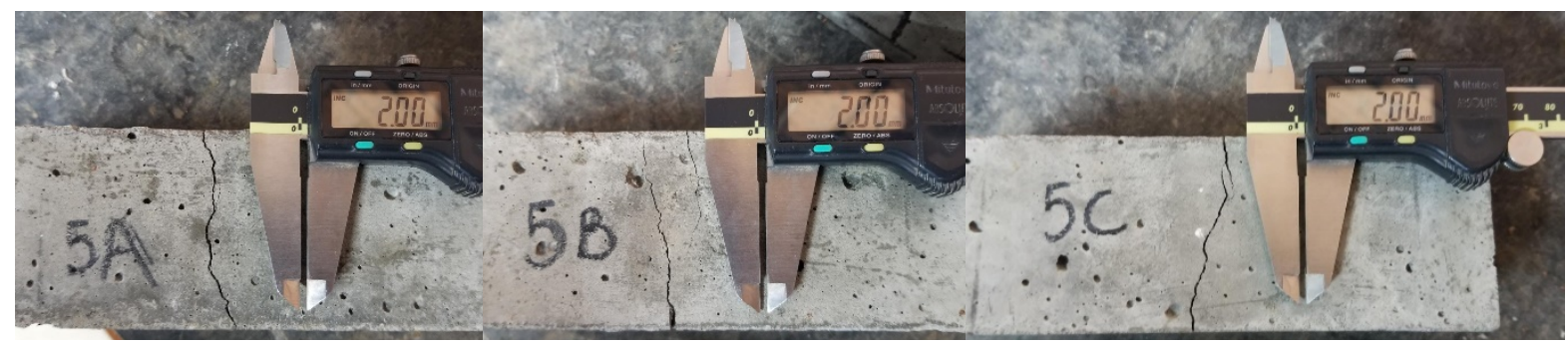

Nas amostras de referência o mecanismo de cicatrização se daria apenas pelo processo autógeno, qual é evidenciado por Li e Yang (2007), que explicam o processo de hidratação das reservas de cimento anidro presentes no concreto, que quando em contato com a água reagem e colmatam as aberturas. Notou-se ainda nesse traço que ele obteve resultados proporcionais aos demais, visto que foram executados da mesma forma e com mesmos traços unitários utilizados nos outros concretos.

\section{CONCLUSÃO}

Tendo realizado as análises e discussões sobre os ensaios e seus referentes resultados, é possível afirmar que a adição de silicato de sódio neutro, apresentam resultados consideráveis, e que contribuem para o aumento do potencial de autocicatrização e autorregeneração. 
O concreto que recebeu a solução de silicato de sódio neutro aspergido, ou seja, a SIL.ASP, obteve bons resultados, e com mais eficiência que os demais, quanto a rapidez na autocicatrização. Esta informação conclui que quando o concreto não possui em sua composição a solução de silicato de sódio neutro, portanto não sendo um concreto autocicatrizante/autorregenerante, ainda é possível agir posteriormente com o método de aspersão.

Vale ressaltar, como já dito no decorrer do trabalho, que a solução de silicato de sódio neutro, quando adicionado diretamente na água de mistura, ou seja, composição apresentada na SIL.ÁGUA, há modificação no processo de cura do concreto, e como avaliado nos ensaios, também modificando as propriedades mecânicas do concreto, pressupondo então, que para adição da solução diretamente, é necessário a realização de mais estudos, para que tal processo não interfira nas propriedades do concreto, quanto a perda de resistência proveniente da adição do silicato de sódio neutro, pois o mesmo evidenciou suas características de autocicatrização e autorregeneração. É importante salientar que os resultados obtidos e apresentados na conclusão deste trabalho se restringem a materiais e metodologias, com número de amostras e ensaios limitados, que por sua vez implicam diretamente nos valores resultantes, e, portanto, não devem ser considerados como valores absolutos. Desta forma, complementa-se a teoria de que para concretização desta avaliação, é necessário a realização de mais estudos, com o objetivo de complementar e sanar qualquer tipo de dúvida sobre esse assunto.

\section{AGRADECIMIENTOS}

Agradecemos ao itt Performance.

\section{REFERENCIAS}

American Concrete Institute. ACI 224: Control of cracking in concrete structures.

ADAK, A. Self Healing Concrete. Jagannath University, Chaksu, Jaipur: 2015, $13 p$.

ALGHAMRI, R.; KANELLOPOULOS, A.; AL-TABBAA, A. Impregnation and encapsulation of lightweight aggregates for self-healing concrete. Construction and Building Materials, v. 124, p. 910-921, 2016.

ASSOCIAÇÃO BRASILEIRA DE NORMAS TÉCNICAS. NBR 5738: Concreto - Procedimento para moldagem e cura de corpos e prova. Rio de Janeiro, 2015.

NBR 5739: Concreto - Ensaio de compressão de corpos de prova cilíndricos - Método de ensaio. Rio de Janeiro, 2018.

NBR 6118: Projeto de estruturas de concreto - procedimento. Rio de Janeiro, 2014.

NBR 12142: Concreto - ensaio de resistência a tração na flexão em corpos de prova prismáticos. Rio de Janeiro, 2010. Janeiro, 2003.

NBR NM 248: Agregados - Determinação da composição granulométrica. Rio de

NBR NM 52. Agregado miúdo - Determinação da massa específica e massa específica aparente. Rio de Janeiro, 2009. de Janeiro, 2006.

NBR NM 45. Agregados - Determinação da massa unitária e do volume de vazios. Rio

NBR 16889 Concreto - Determinação da consistência pelo abatimento do tronco de cone. Rio de Janeiro, 2020

BONIĆ, Z. et al. Damage of concrete and reinforcement of reinforced-concrete foundations caused by environmental effects. Procedia Engineering, v. 117, n. 1, p. 416-423, 2015. 
BUREAU OF INDIAN STANDARDS. IS 456: Plain and Reinforced Concrete - Code of Practice. New Delhi: Bureau Of Indian Standards, 2000.

DE MUYNCK, W. et al. Bacterial carbonate precipitation as an alternative surface treatment for concrete. Construction and Building Materials, v. 22, n. 5, p. 875-885, 2008.

FIB- FEDERATION INTERNATIONALE DU BETON- 34 - Bulletins : Model Code for Service Life Design.

GIANNAROS, P; KANELLOPOULOS, A; AL-TABBAA, A. Sealing of cracks in cement using microencapsulated sodium silicate. In: Department of Engineering, University of Cambridge, Trumpington Street, Cambridge CB2 1PZ, UK 2016.

GUPTA, S.; PANG, S. D.; KUA, H. W. Autonomous healing in concrete by bio-based healing agents - A review. Construction and Building Materials, v. 146, p. 419-428, 2017.

HAVLÁSEK, P. et al. Thermo-mechanical simulations of early-age concrete cracking with durability predictions. IOP Conference Series: Materials Science and Engineering, v. 236, n. 1, 2017.

HOPPE FILHO, Juarez et al. Atividade pozolânica de adições minerais para cimento Portland (Parte II): Índice de atividade pozolânica com cimento Portland (IAP), difração de raios-X (DRX) e termogravimetria (TG/DtG). Materia-Rio de Janeiro, v. 22, p. e11873, 2017.

KANELLOPOULOS A, QURESHI T S; AL-TABBAA A. Glass encapsulated minerals for self-healing. In: cement based composites Constr. Build. Mater. 98 780-91 2015.

Li V.C. \& Yang E. 2007. Self healing in concrete materials. In S. van der Zwaag (ed.) Self healing materials - An alternative approach to 20 centuries of materials science. Springer, The Netherlands; pp: 161-194.

MANOJ PRABAHAR, A. et al. An experimental study of self healing of cracks in concrete using sodium silicate capsule. Rasayan Journal of Chemistry, v. 10, n. 2, p. 577-583, 2017.

MEDEIROS, M.H.F; PEREIRA, E; HELENE, P. Tratamento de superfície com silicato de sódio para concreto: penetração de cloretos e absorção de água. Revista Alconpat, vol 2, no3, pp 149$161,2012$.

MEHTA, P.K.; MONTEIRO, P.J.M. Concreto: microestrutura, propriedades e materiais. In: HASPARYK, N. P. (Ed). 2. ed. São Paulo: Ibracon, 2014.

PACHECO, F. Análise da eficácia dos mecanismos de autocicatrização do concreto. Tese (doutorado) Universidade do Vale do Rio dos Sinos, Programa de Pós-Graduação em Engenharia Civil, São Leopoldo, RS, 2020, 348p.

PROVIS, J.L; VAN DEVENTER, J.S.J. Alkali-activated materials. State-of-art report, RILEM TC 224AAM. Springer, 2014.

SENGUL, O. et al. Effect of expanded perlite on the mechanical properties and thermal conductivity of lightweight concrete. Energy and Buildings, v. 43, n. 2-3, p. 671-676, 2011.

WU, M.; JOHANNESSON, B.; GEIKER, M. A review: Self-healing in cementitious materials and engineered cementitious composite as a self-healing material. In: Construction and Building Materials, v. 28.2012.

ZAI, S. A. K.; MURTHY, M. K. Self-healing concrete. Journal of Civil Engineering and Environmental Technology, v. 2, n. 27-33, 2015. 